Advance Journal of Food Science and Technology 16(SPL): 173-177, 2018

DOI:10.19026/ajfst.16.5952

ISSN: 2042-4868; e-ISSN: 2042-4876

(C) 2018 Maxwell Scientific Publication Corp.

Submitted: September 14, $2017 \quad$ Accepted: December 15, $2017 \quad$ Published: November 10, 2018

\title{
Research Article \\ Food and Nutrition Security in Families with Boys and Girls under 10 Years of Age with Malnutrition in Galapa, Atlántico Colombia
}

\author{
Aleyda Parra Castillo and Sandra Gómez Aguirre \\ Master's Program in Food and Nutritional Security, Nutrition and Dietetics School (Programa de \\ Nutrición y Dietética), University of Atlántico -Universidad del Atlántico-Cra. 30, Nº 8-49, Puerto \\ Colombia, Atlántico, Colombia
}

\begin{abstract}
The objective of the study was to determine the level of food and nutritional security in families of children under 10 years of age with malnutrition attended in the program for growth and development of the hospital State Social Enterprise of Galapa (ESE Galapa) in Galapa (Atlántico, Colombia). A descriptive cross-sectional study was carried out with a sample randomly selected of 170 families that attended the program during 2015 , with $70 \%$ of minimum attendance required. The variables considered were, social and demographic conditions, nutritional status and level of food security. Food security status was classified using the Latin-American and Caribbean Scale of Food Safety (ELCSA) as an instrument for data collection. Forty-five-point three percent of the families presented food and nutritional insecurity, families with children in risk of malnutrition and obesity presented major trend of food and nutritional severe insecurity. The prevalence of the nutritional condition as well as the food and nutritional insecurity of this population is related directly on the parent's occupation, their income and their ages, since $57.64 \%$ was unemployed, $39.41 \%$ of the parents only earn a minimum wage and $68.3 \%$ are between 15 and 30 years old. The study showed that families with boys and girls with malnutrition are on low food insecurity level corresponding to $25.9 \%$ among all.
\end{abstract}

Keywords: Food and nutrition programs, food insecurity, nutritional status, school-age children

\section{INTRODUCTION}

For the estimation of World Food Security, the UN Food and Agriculture Organization (FAO) uses the number of undernourished people, which means that the calorie intake is less than the minimum needed. The latest FAO reports indicated a reduction in global hunger, between 2012 and 2014, estimated that about 805 million people were chronically malnourished, a decrease of $>100$ million in the last decade and 209 million < in 1990-92. (FAO, 2014) "Over the same period, the prevalence of undernourishment has fallen from 18.7 to $11.3 \%$ worldwide and from 23.4 to $13.5 \%$ in developing countries".

A study conducted in Mexico in 2013, on the magnitude of Food Insecurity (FI), its relationship with the state of nutrition and socioeconomic factors, reported that "One in three households suffers from Food Insecurity (FI) in its moderate or severe form, in addition to chronic malnutrition in children under 5 years affects 1.5 million children". Even though, there have been significant reductions in the last quarter of the century (in 1988, the prevalence of chronic malnutrition was $26.8 \%$ and in 2012 it was $13.6 \%$ ). the problem is still a huge health issue. In addition to the above, $9.8 \%$ of preschoolers were overweight, $34.4 \%$ of school-age children, $35.9 \%$ of adolescents and $71.3 \%$ of adults are overweight and obese "(Shamah-Levy et al., 2014).

Likewise, in Mexico in 2012 (a research was conducted on the epidemiology of food security, which determined that at the national level, $41.6 \%$ of Mexican households classified as mild food insecure, $17.7 \%$ as moderate $\mathrm{AI}$ and $10.5 \%$ in severe AI (Mundo-Rosas et al., 2013).

In Colombia, research on malnutrition and food security was carried out at Universidad Industrial de Santander (Fonseca et al., 2013). A multilevel study where the scales for the Perception of Food Safety (EPSA) was used as instruments for data collection along with the Latin American and Caribbean Food Security Scale (ELCSA in Spanish). Allowed measuring Food Insecurity (FI) in the households, as well as an instrument that analyzed the sociodemographic characteristics of the family. This study showed that the weight deficit and excess for

Corresponding Author: Aleyda Parra Castillo, Nutrition and Dietetics School, Universidad del Atlántico, Cra 30 No.8-49 Puerto Colombia, Atlántico, Colombia, Tel.: (57) 5-3852266 Ext. 1027

This work is licensed under a Creative Commons Attribution 4.0 International License (URL: http://creativecommons.org/licenses/by/4.0/). 
individuals in the same age range are very similar to those reported by the National Nutrition Situation Survey in Colombia (ICBF, 2010) and corroborates the bias for the distribution of weight/height, recognized as obesity. This study showed that weight excess gradually increases with age, with a clear trend: at the age of 18 , the probability of excess increases by 3.6 times and the risk rises from 9.1 to $33.1 \%$.

According to another study carried out in Pereira Colombia, on Validation of the Latin American and Caribbean Scale of Food Security in pregnant adolescents, they stated that food security is measured according to the capacity of families to guarantee sufficient food supply during the year and from 1 year to the next. Also, they allow satisfying all the needs and requirements of calories, nutrients and micronutrients of every member of the family (Muñoz-Astudillo et al., 2010).

For all the above, the national food and Nutrition Security Policy (PSAN in Spanish) (Colombia, 2008) requires social and economic interventions associated with food and nutrition security for vulnerable population groups. For that reason, the objectives of the policy imply that all projects, plans and actions have to articulate with each other. That the production of food of the basic basket is sustainable and competitive, develop skills in the population for the production of food to guarantee self-consumption, create conditions for the educational development of the population and improve academic performance and improve access and quality of health services, among others.

The primary objective of this investigation was to determine the Food and Nutrition Security in families with children under 10 years of age, presenting malnutrition and attended by the State Social Enterprise (ESE in Spanish) of the Municipality of Galapa Atlántico in 2016. This result will serve as Baseline for the implementation of strategies of prevention and nutritional recovery in the ESE and will help to rethink the intervention plans for children with malnutrition problems.

This study observed the behavior of the level of Food and Nutrition Security of families with children under ten years according to household and individual's sociodemographic characteristics, housing characteristics and state of malnutrition due to deficit or excess.

\section{MATERIALS AND METHODS}

The research corresponds to a cross-sectional study in which simultaneously observed the situation of Food and Nutrition Security of families and the nutritional status of children. The population of the study was 305 families with children $<10$ years of age with malnutrition attended in the program for growth and development of the hospital State Social Enterprise of Galapa (ESE Galapa) in Galapa (Atlántico, Colombia).

The study sample was 170 families selected by simple random type sampling. The sample size was calculated based on a prevalence of $50 \%$ of the cases of malnutrition of the Galapa ESE taken, a 95\% CI, and a sampling error of $5 \%$. The hospital provided a database where the name of each child found. The data was collected through a survey applied to the malnourished children's' caregivers at Galapa's ESE at 2015.

The data included address, mother's name, telephone number and neighborhood. The exclusion criteria included: children with disabilities, denial from parents or legal guardian to participate in the study.

The variables considered in the study were:

- Sociodemographic characteristics: Age, gender, ethnicity, caregiver occupation and schooling, family income, family type, number of children under 10 years old and affiliation to the general social and health system.

- Characteristics of the house: Number of people sharing the same roof, type of dwelling, as well as the characteristics of the responsibility for the home.

- The nutritional security situation: Evaluated through the perception of food insecurity using the ELCSA scale that includes variables such as money available for food purchase, food variety, hunger, food shortage, food practices, eating stoppage, food portion and meal times (FAO, 2012).

The direct evaluation of the nutritional status of children was determined by anthropometric measurements. In this regard, a nutritional status determined by height-for-age index and BMI-for-age index. The obtained data allowed the identification of optimal nutritional status, thinness, overweight or obesity. The analysis was done according to the Colombian resolution 2121 from 2010 (Colombia, 2010) on which Colombia adopted the patterns of growth and development of the World Health Organization-WHO 2006-2007. The anthropometric measurement was done using a digital scale (SECA ${ }^{\circledR}$ ) to determine participant's weight and stadiometer (SECA $\left.{ }^{\circledR}\right)$ to assess participant's height.

This study was endorsed by the Ethics Committee at Universidad del Atlántico, taking into account resolution No. 8430 of 1993 of the Ministry of Health in Colombia, Title II, of research on human beings, article 11. It considered that this study has no ethical risk (Colombia, 1993).

The information obtained was tabulated and analyzed using Microsoft Excel 2007® program and Epi Info version 7.0 and the variables were assigned a code for better management. 


\section{RESULTS AND DISCUSSION}

The food and nutritional security of families with malnourished children, who enrolled in the growth and development program of the ESE Hospital in Galapa considerably threatened. The results showed that only $45.3 \%$ are in food and nutritional security and $54.7 \%$ are in food and nutrition insecurity. This category distributed as follows: mild $25.3 \%$, moderate $9.4 \%$ and severe $20 \%$. Contrasting these results with the study carried out in Peru in 2014 in families of the Morochucos district in Ayacucho (Pillaca and Villanueva, 2015), where only $39.1 \%$ are in food security. Thirty-seven-point five percent with food insecurity without hunger, $18.8 \%$ with food insecurity with moderate hunger and $4.7 \%$ with food insecurity with severe hunger. According to this comparison, it is observed that although the prevalence of low and moderate insecurity is lower than in the Pillaca study, the severe FI is 15.3 percentage points higher in this study Fig. 1.

Regarding the food and nutritional security situation according to the nutritional status of children under 10 years of age, the following was observed: the

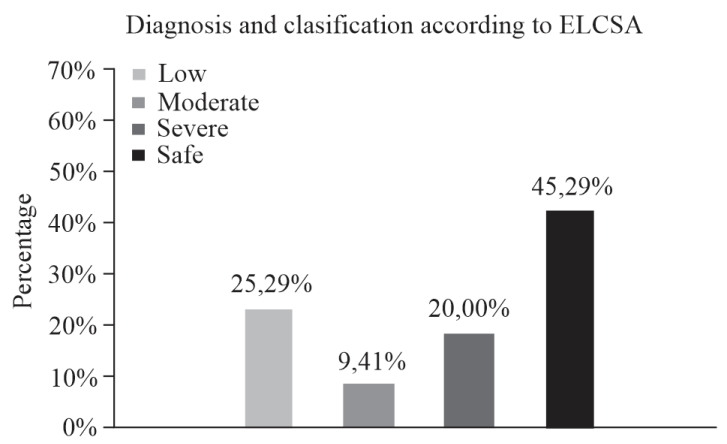

Fig. 1: Perception of food insecurity according to the ELCSA scale in the families with children under 10 years of age at the ESE of Galapa, Atlántico, 2016 Own source

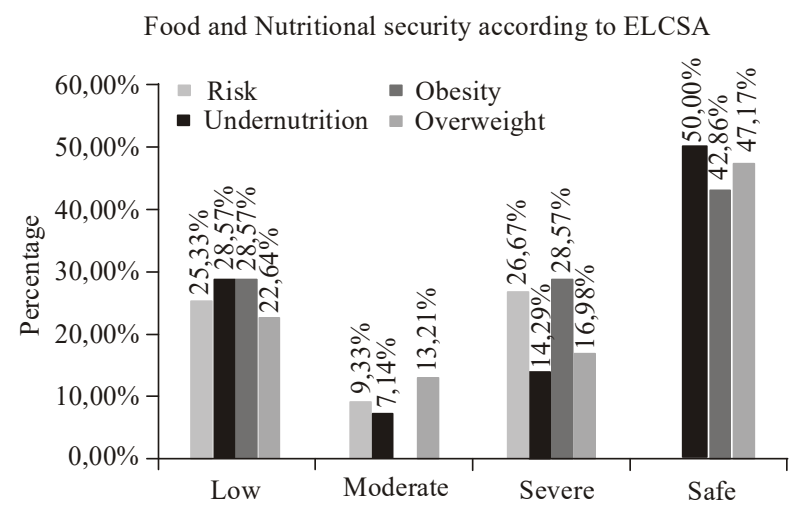

Fig. 2: Status of food and nutritional security according to the nutritional status of children under 10 years of age at the ESE of Galapa, Atlántico, 2016 Own source highest prevalence of Food Insecurity and severe dietary insecurity (FI) was found in families with children at risk of malnutrition, $26.7 \%$ ( $\mathrm{n}=17$ cases). The highest proportion of mild food insecurity presented in children with hunger, $28.6 \%$. Children with obesity were found to have moderate and severe FI with $28.6 \%$ and finally, families with overweight children found in mild FI, 22.6\%. The moderate FI was higher in children with overweight with $13.21 \%$ (7 cases). It is noteworthy that the highest proportion of food security founded in households with malnourished children with $50 \%$ (14 cases). Comparing these results with those of the research conducted in Mexico in 2014 (Cuevas-Nasu et al., 2014) on Food Insecurity and nutritional status in children under 5 years of age, found that 3 of every 4 Mexican households with children under 5 live in food insecurity and chronic malnutrition is $43 \%$ higher in children under 5 years of age. CuevasNasu et al. (2014) did not find a food insecurity relationship with overweight in children under 5 years old, unlike this study, which did show the relationship of FI with overweight. View FI in Fig. 2.

Table 1 shows the most relevant variables of the socio-demographic characteristics that influence the food security of this population. It noticed that unemployment was the primary factor affecting the food insecurity prevalence, with $57.1 \%$. It also saw that women care for $55.8 \%$ of the homes, with age ranging from 15 to 30 years old. The households with the highest percentage of food insecurity were those whose caregivers did not complete their secondary education with $57.4 \%$. However, something that called the attention in this study was that $14.1 \%$ of families, with Food Security, were those that concluded some studies. The educational level could be related to the food security of Households.

These results coincide with those presented by the ENSIN 2010 in which they showed that according to the occupation that the head of the household had, the highest prevalence's of ISA reported for the households that the head was looking for work. The prevalence of ISA is lower as the level of education of parents increases. In households whose parents did not have to school or who had only attended preschool, the prevalence was $66.6 \%$ and in those with postgraduate studies, it was $7.6 \%$ (ICBF, 2010).

When the residential area introduced in the analysis, it founded that $32.35 \%$ of these families live in rural areas $(n=55)$. The prevalence of food insecurity is higher in families in rural areas with $70.9 \%$. These represent $15 \%$ of the total vulnerability of families. About $30 \%$ of these families are in severe insecurity, doubling the proportion of families in that condition in the rural area. On the other hand, 53.04\% of the families living in urban areas are in food and nutritional security. The values are presented in Fig. 3. 
Res. J. Appl. Sci. Eng. Technol., 16(SPL): 173-177, 2018

Table 1: Food and nutritional security of families according to the socio-demographic characteristics of the caregivers of children under 10 with malnutrition attended at the ESE of Galapa, Atlántico, 2016

\begin{tabular}{|c|c|c|c|c|c|c|c|c|c|c|}
\hline \multirow[b]{3}{*}{ Characteristics } & \multicolumn{10}{|c|}{ Classification according to SAN ELCSA } \\
\hline & \multicolumn{2}{|c|}{ Mild } & \multicolumn{2}{|c|}{ Moderate } & \multicolumn{2}{|c|}{ Severe } & \multicolumn{2}{|c|}{ Safe } & \multicolumn{2}{|c|}{ Total } \\
\hline & FR & $(\%)$ & FR & $(\%)$ & FR & $(\%)$ & FR & $(\%)$ & FR & $(\%)$ \\
\hline \multicolumn{11}{|c|}{ Occupation of the caregiver } \\
\hline Unemployed & 23 & 53.4 & 10 & 62.5 & 23 & 67.6 & 42 & 54.5 & 98 & 57.6 \\
\hline Employee & 8 & 18.6 & 3 & 18.7 & 7 & 20.5 & 23 & 29.8 & 41 & 24.1 \\
\hline Self-dependent & 12 & 27.9 & 3 & 18.7 & 4 & 11.7 & 11 & 14.2 & 30 & 17.6 \\
\hline Student & 0 & 0.0 & 0 & 0.0 & 0 & 0.0 & 1 & 1.30 & 1 & 0.5 \\
\hline Total & 43 & 100.0 & 16 & 100.0 & 34 & 100.0 & 77 & 100.0 & 170 & 100.0 \\
\hline \multicolumn{11}{|l|}{ Age of the caregiver } \\
\hline $15-30$ & 21 & 72.4 & 13 & 86.6 & 10 & 50.0 & 40 & 67.7 & 84 & 68.2 \\
\hline $31-45$ & 6 & 20.7 & 1 & 6.6 & 6 & 30.0 & 10 & 16.9 & 23 & 18.7 \\
\hline $46-60$ & 2 & 6.9 & 0 & 0.0 & 2 & 10.0 & 9 & 15.2 & 13 & 10.5 \\
\hline $61-75$ & 0 & 0.0 & 3 & 6.6 & 0 & 10.0 & 0 & 0.0 & 3 & 2.4 \\
\hline Total & 29 & 100.0 & 15 & 100.0 & 20 & 100.0 & 59 & 100.0 & 123 & 100.0 \\
\hline \multicolumn{11}{|c|}{ Educational level of the caregiver } \\
\hline No studies & 1 & 2.3 & 2 & 12.5 & 0 & 0.0 & 0 & 0.0 & 3 & 1.7 \\
\hline Incomplete primary & 4 & 9.3 & 1 & 6.2 & 10 & 29.4 & 5 & 6.4 & 20 & 11.7 \\
\hline Primary & 6 & 13.9 & 0 & 0.0 & 5 & 14.7 & 11 & 14.2 & 22 & 12.9 \\
\hline Incomplete high school & 10 & 23.2 & 6 & 37.5 & 11 & 32.3 & 20 & 25.9 & 47 & 27.6 \\
\hline High school & 15 & 34.8 & 5 & 31.2 & 7 & 20.5 & 24 & 31.1 & 51 & 30.0 \\
\hline Technician & 4 & 9.3 & 2 & 12.5 & 0 & 0.0 & 13 & 16.8 & 19 & 11.1 \\
\hline Technologist & 3 & 6.9 & 0 & 0.0 & 0 & 0.0 & 2 & 2.6 & 5 & 2.9 \\
\hline University without title & 0 & 0.0 & 0 & 0.0 & 0 & 0.0 & 2 & 2.6 & 2 & 1.1 \\
\hline University graduate & 0 & 0.0 & 0 & 0.0 & 1 & 2.9 & 0 & 0.0 & 1 & 0.5 \\
\hline Total & 43 & 100.0 & 16 & 100.0 & 34 & 100.0 & 77 & 100.0 & 170 & 100.0 \\
\hline
\end{tabular}

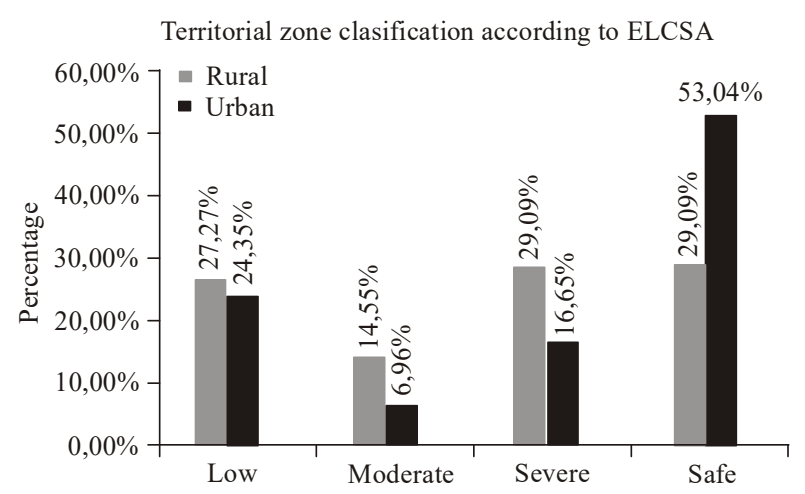

Fig. 3: The situation of food and nutritional security according to the area of residence in the families of children under 10 years of age at the ESE Galapa, Atlántico, 2016

Own source

\section{CONCLUSION}

The study showed that $55 \%$ of the population is under food insecurity. This value is similar to the results obtained in Perú, in the district of Morochucos, Ayacucho, where $61 \%$ of its population is under food insecurity (Pillaca and Villanueva, 2015).

Families with children at risk of malnutrition were those with the highest tendency of severe food insecurity and cases of overweight and obesity presented FI in similar proportions, ranging from low to severe.

The prevalence of malnutrition and food and nutritional insecurity of this population depends on the occupation of the parents, their income and their ages. Due to the fact that more than a half of the parents were unemployed.

It also evidenced that in this population, children under 10 years old, are under food insecurity and are malnourished when their parents are between 15 and 30 years old, young parents with only high school studies.

However, this study showed that the least percentage of families with food insecurity were those who finished some education, indicating that the educational level is a determining factor for household food security.

These results coincide with those presented by the ENSIN 2010, in which they showed that the prevalence of food insecurity is lower as the level of parental schooling increases. In households whose parents did not have schooling or who had only attended primary school, the prevalence was $66.6 \%$ and in those with graduate studies, it was $7.6 \%$.

In this study, food and nutritional insecurity (mild, moderate and severe) is accentuated in the rural area, which could indicate that the governmental entities need to pay attention to these areas of high vulnerability.

\section{ACKNOWLEDGMENT}

The author wants to acknowledge the support from the director of ESE Galapa Atlántico for authorizing the completion of this research and his unconditional support. 


\section{CONFLICT OF INTEREST}

The authors declare no conflicts of interest.

\section{REFERENCES}

Colombia, 1993. Colombian Resolution 8430: Scientific, Technical and Administrative Standards for the Health Research. Health Ministry, Colombia, pp: 19.

Colombia, 2008. Colombian National Policy on Food and Nutrition Security. CONPES Social 113, National Council of Colombian Social Economic Policy. Bogotá, Colombia: Consejo Nacional de Política Económica Social. República de Colombia. Departamento Nacional de Planeación, pp: 47.

Colombia, 2010. Colombian Resolution 2121: Growth Patterns Published by WHO for Children Between 0 and 18 Years of Age: Ministry of Social Protection, pp: 51 .

Cuevas-Nasu, N.L., J.A. Rivera-Dommarco, T. Shamah-Levy, V. Mundo-Rosas and I.M.G. Humarán, 2014. Inseguridad alimentaria y estado de nutricion en menores de cinco años de edad en México. Salu Pub Mex., 56: 49-53.

FAO, 2012. Escala Latinoamericana y Caribeña de Seguridad Alimentaria (ELCSA). Manual de Uso y Aplicaciones, pp: 20.
FAO, 2014. El estado de la inseguridad alimentaria en el mundo 2014. Fortalecimiento de un entorno favorable para la seguridad alimentaria y la nutrición. Rome Italy. Retrieved form: http://goo.gl/ysbGa0.

Fonseca, C.Z.Y., B.G.A. Patiño and F.O.F. Herrán, 2013. Malnutrición y seguridad alimentaria: un estudio multinivel. Rev. Chil. Nutr., 40(3): 208, 212-214.

ICBF, 2010. National Survey of the Nutritional Situation in Colombia (ENSIN). Instituto Colombiano de Bienestar Familiar, Bogotá, Colombia, pp: 23.

Mundo-Rosas, V., T. Shamah-Levy and J.A. RiveraDommarco, 2013. Epidemiología de la inseguridad alimentaria en México. Salud Pública de México, 55(Supl. 2).

Muñoz-Astudillo, M.N., J.W. Martínez and A.R. Quintero, 2010. Validación de la Escala Latinoamericana y Caribeña de Seguridad Alimentaria en gestantes adolescentes. Rev. Salud Pública, 12(2): 173-183.

Pillaca, S. and M. Villanueva, 2015. Evaluación de la seguridad alimentaria y nutricional en familias del distrito de los morochucos en Ayacucho, Perú. Rev. Per. Med. Exp. Salu. Púb., 32(1): 73-78.

Shamah-Levy, T., V. Mundo-Rosas and J.A. RiveraDommarco, 2014. La magnitud de la inseguridad alimentaria en México: su relación con el estado de nutrición y con factores socioeconómicos. Salud Pública de México, 56(Supl. 1): s79-85. 